\title{
İkame Etkisi, Baskı Etkisi ve Bu Etkiler ile Sendikalaşma Eğilimi Arasındaki İlişki ${ }^{1}$
}

Sadık KILIÇ, Department of Labour Economics and Industrial Relations, Faculty of Economics and Administrative Sciences, Bulent Ecevit University, Turkey; e-mail: sadik.kilic@beun.edu.tr

Kemal YILDIZ, Provincial Office of Istanbul, Turkish Labour Agency,Turkey; e-mail: kemal.yildiz@iskur.gov.tr

\section{Substitution Effect and Suppression Effect, and the Relationship between These Effects and Willingness to Unionize ${ }^{2}$}

\begin{abstract}
The aim of this study is to explore the levels of workers' willingness to unionize, their perceptions about substitution effect and suppression effect, and the relationship between the willingness and the effects. To do so, a survey was conducted among 215 workers. Descriptive statistics were used to determine the mentioned levels, and multiple linear regression analysis was utilized to reveal the mentioned relationship. At the end of the research, we discover that there is a high level of suppression effect and a low level of substitution effect among workers and a stronger tendency on willingness to unionize, and the willingness is robustly predicted by suppression effect.
\end{abstract}

Keywords

Substitution Effect, Suppression Effect, Willingness to Unionize, Union Revitalization.

JEL Classification Codes : J53.

\section{Öz}

$\mathrm{Bu}$ çalışmanın amacı, işçilerin sendikalaşma eğilimlerinin ve ikame etkisi ve baskı etkisine yönelik algılarının düzeyini belirlemek ve bu etkilerle sendikalaşma eğilimi arasındaki ilişkiyi ortaya çıkarmaktır. $\mathrm{Bu}$ amaçla 215 işçiye anket uygulanmıştır. Bahsi geçen düzeyleri belirlemek için tanımlayıcı istatistiklerden, bahsi geçen ilişkiyi tespit etmek için çoklu doğrusal

I Bu çalışma, Bülent Ecevit Üniversitesi Bilimsel Araştırma Projeleri Koordinatörlüğü tarafindan desteklenmiş olup daha önce Sosyoekonomi Derneği ve Hacettepe Üniversitesi Piyasa Ekonomisini ve Giriş̧imciliği Gelişstirme Merkezi tarafindan Almanya'nın Münih şehrinde, 29-30 Ekim 2015 tarihlerinde düzenlenen "Birinci Uluslararası Sosyoekonomi Derneği Yıllık Buluşması"nda sunulmuş olan çalışmanın gözden geçirilmiş halidir.

2 This is the revised version of the paper which is supported by Bulent Ecevit Univesity Scientific Research Projects Coordination Unit and presented in "First International Annual Meeting of Sosyoekonomi Society" which was held by Sosyoekonomi Society and CMEE - Center for Market Economics and Entrepreneurship of Hacettepe University, in Munich/Germany, on October 29-30, 2015. 
regresyon analizinden yararlanılmıştır. Araştırmanın sonunda, işçilerin üzerinde çok yüksek düzeyde bask1 etkisi olduğu ve çok düşük düzeyde ikame etkisi bulunduğu ve işçilerin sendikalaşma eğiliminin hayli yüksek olduğu tespit edilmiş ve sendikalaşma eğiliminin, baskı etkisi tarafından anlamlı bir şekilde açıklanmakta olduğu görülmüştür.

Anahtar Sözcükler : İkame Etkisi, Baskı Etkisi, Sendikalaşma Eğilimi, Sendikaların Yeniden Canlanması.

\section{Giriş}

Sendikal yoğunlukta yaşanan düşüşler, ikame etkisiyle açıklanabilir mi? $\mathrm{Bu}$ soruya daha önce pek çok kez cevap aranmıştır. Hatta bazı araştırmalar doğrudan bu konuya yönelmiştir (Bryson, vd., 2004; Dundon, 2002; Dundon \& Rollinson, 2004; Fiorito, 2001, 2003; Gall, 2002; Gall \& McKay, 2001; Machin \& Wood, 2005; Roche, 2001). Fakat sorunun cevabı bu araştırmaların hiçbirinde başka bir olguyla ilişki kurulmadan verilememiştir: İşveren direnci (veya baskı etkisi). İkame etkisi, öz itibariyle insan kaynakları yönetimi (İKY) ve onun paydaşlık söylemi ile ilgilidir. Özellikle yumuşak IKY modeli ve buna bağlı geliştirilen söylemler ikame etkisi çerçevesinde değerlendirilebilir (Fiorito, 2001; Roche, 1998, 2001). Bask1 etkisi ise, işverenlerin sert yöntemlerle (tehdit, yıldırma, işten uzaklaştırma gibi) sendikadan kurtulmasını konu alır (Blyton \& Turnbull, 2004; Bronfenbrenner, 2009; Bronfenbrenner \& Juravich, 1994; Dundon, 2002; Dundon \& Rollinson, 2004: Fiorito, 2001; Freeman, 2007; Freeman \& Kleiner, 1988; Gall, 2002, 2003, 2004; Gall \& McKay, 2001; Machin \& Wood, 2005; McLoughlin \& Gourlay, 1992; Roche, 1998, 2001).

$\mathrm{Bu}$ iki argüman, birbirinin rakibi iki farklı teoriden veya iki farklı referans çerçevesinden ortaya çıkmaktadır³. Birkaç cümleyle bu teorilerin farkını ortaya koymak mümkün değildir. Fakat öz itibariyle, ikame etkisi argümanının, 'yeni' endüstri ilişkileri ve İKY yaklaşımından önemli ölçüde beslendiği; baskı etkisi argümanının ise temelde endüstri ilişkileri radikalizminden ilham aldığı rahatlıkla söylenebilir. Zira ikame etkisi argümanı, işçi ile işverenler arasındaki çıkar farklılığını yeterince gündeme getirmez ve genellikle tekilci söylemlere bağlı kalır. Bu argümanın arkasında yatan temel düşünce, sendikaların herhangi bir çalışma ilişkisinde ikincil örgütler olarak değerlendirilmesi ve sendikaya yönelimin temel nedeni olarak iş tatminsizliğinin görülmesidir (Fiorito, 2001: 335). Yani bu görüşe göre, bir çalışma ilişkisinde zaten işveren tarafından kurulmuş bir örgütlenme söz konusudur ve sendikalar bu ilişkiye haksız bir müdahalede bulunurlar. Özellikle İKY teknikleri ile iş tatmini arasında apriori olarak kurulan pozitif ilişki, ikame etkisi argümanın odağını oluşturmaktadır. Sendikal yoğunluktaki düşüş, ikame etkisi argümanına göre, kısaca, yönetim felsefesindeki değişimden ileri gelir ve işçiler 'gönüllü'

3 Bu konu çok boyutludur ve geçmişi on dokuzuncu yüzyıla dayanan "tekilcilik-çoğulculuk ikilemi”" gibi meseleleri içermektedir. Daha fazla ayrıntı için bkz. Fox, 1974; Kaufman, 2008; Yıldırım, 1997. 
bir şekilde sendikasız olmayı seçerler. Yani sendikal yoğunluktaki düşüş, işçilerin sendika talebindeki azalmanın bir sonucudur.

Baskı etkisi argümanında ise, İKY teknikleri hakkında yürütülen tartışmalar "söylem ve gerçeklik (rethoric and reality)" şeklinde ikiye ayrılır ve ikisi arasında büyük boşluklar olduğuna dikkat çekilir (Blyton ve Turnbull, 2004; Legge, 1995). Benzer şekilde, İKY'nin yumuşak ve sert olmak üzere iki farklı yönüne vurgu yapılır ve yumuşak İKY'nin sadece söylem düzeyinde gerçekleştiği iddia edilir (Greenwood, 2002). Emek süreci teorisi ve mobilizasyon teorisi gibi önemli teorilerden yararlanılır (Braverman, 1998; Kelly, 1998) ve çalışma ilişkisi asimetrik bir güç mücadelesi olarak kavramsallaştırılır (Kelly, 1998). İKY uygulamalarının örgütsel bağlılığı arttırmadığı ve iş tatminini güçlendirmediği aksine emek üzerinden artan rekabet sonrası düşürdüğü vurgulanır (Gallie, 2001; Thompson \& Harley, 2007). Örgütsel bağlılığın karşılıklı olarak oluşan 'güven' ikliminden doğduğu ve fakat IKKY'nin karşılıklı güven ortamına yol açmadığı söylenir (Badigannavar \& Kelly, 2005; Baruch, 1998). Daha önemlisi, sendikaların temsilcilik alanlarından dışlandıkları ve sendikalı işçilerin çok çeşitli yöntemlerle baskı altına alındıklarını gösteren ampirik kanitlar elde edilir (Bryson ve Gomez, 2004; Bronfenbrenner, 2009; Freeman, 2007; Gall ve McKay, 2001). Kısaca, baskı etkisi argumanına göre, sendikal yoğunluktaki düşüşün en önemli nedenlerinden birisi işverenlerin zorlama, baskı ve yıldırma gibi yöntemlerle işçileri sendikalı olmaktan alıkoymalarıdır.

İkame etkisi argümanı, öz itibariyle, çalışma ilişkilerinde ve toplumda önemli yapısal dönüşümlerin (sanayi-ötesi toplum, post-Fordizm ve post-modernizm gibi) vurgulandığı bazı çerçeve söylemlerden doğmuştur (bkz. Beck, 1987; Brown, 1990). Bu çerçeveler, sendikaların günümüz toplumlarındaki işlevlerini yavaş yavaş yitirdiklerini, daha uygun bir ifadeyle yavaş yavaş tarih sayfalarına karıştığını iddia etmektedirler. Oysa baskı etkisi argümanını kullanan yazarlar, sendikaların yeniden canlanması (union revitalisation) tartışmalarına da ortak olmaktadırlar (Frege \& Kelly, 2003; Heery vd., 2003). Sendikaların yeniden canlanması tartışması, sendikaya üye olmak isteyen fakat üyeliği engellenen çok sayıda işçinin varlığını kabul eder. Yani bu görüşe göre, eğer işçiler sendikalı olma hususunda kararlarını tamamen özgür bir şekilde verebiliyor olsalardı, onların çoğunluğu sendikaya üye olmakta çok az tereddüt gösterirlerdi. Dolayısıyla baskı etkisi argümanı sendikaların yeniden canlanması iddiasının ön koşulu gibidir. $\mathrm{Bu}$ doğrultuda, sendikalara örgütlenmemiş alanlarda örgütlenme stratejileri geliştirme, örgütsel yeniden yapılanma (buna sendikaların demokratikleşmesi de denilebilir), sendikal birleşme, uluslararası sendikacılık ve dayanışma, devlete ve işverenlere karşı daha sert bir sendikacılık ve sosyal hareket sendikacılığı gibi çok sayıda stratejik tercih önerilmektedir (Frege \& Kelly, 2004). Kısaca, buradaki esas vurgu, işçiler arasında sendikalaşma eğiliminin giderek güçlendiği fakat bunun üyeliğe dönüşümünün pek çok nedenle engellendiğidir.

Bu çalışma, birbiriyle ilgili bu konular etrafında bazı özel amaçlar içermektedir. Öncelikli amaç, işçiler arasında ikame ve baskı etkilerinden hangisinin daha güçlü bir şekilde algılandığını tespit etmektir. $\mathrm{Bu}$ tespit, daha önce yapılan araştırmaların 
bulgularıyla birlikte (Fiorito, 2001; Machin \& Wood, 2005), sendikaların geleceği ile ilgili yürütülen olası tartışmalar için bir gösterge olma potansiyeline sahip olabilecektir. İkinci amaç, sendikalaşma eğiliminin düzeyini belirlemektir. Bu amaç gerçekleştiği takdirde, son zamanlarda arttığı vurgulanan sendika talebinin (Charlwood, 2002, 2003; Freeman, 2007; Turner \& D’Art, 2012) Türkiye'deki çalışma ilişkilerine teşmil edilip edilemeyeceği hakkında bilgi edinilebilecektir. Çalışmanın üçüncü ve son amacı ise ikame ve baskı etkilerinin sendikalaşma eğilimi üzerindeki etkisini tespit etmektir. Bu son amaç, daha önce açıklanan sendikaların tarih sayfalarına karışması ve sendikaların yeniden canlanması tartışmaları dikkatli okunduğunda oldukça önemli bir içeriğe sahiptir. Zira ikame etkisi argumanını kullananlar, üstü açık ya da örtülü sendikalaşma eğiliminin ikame etkisi yüzünden gerilediğini iddia ederken, baskı etkisi argümanını kullananlar baskı etkisinin sendikalaşma eğilimini kuvvetlendirici bir etki yaptığını ve sonuçta sendikaların yeniden canlanması tartışmalarını başlattığını ileri sürmektedirler.

\section{Yöntem}

\subsection{Veri Toplama ve Analiz}

$\mathrm{Bu}$ araştırmada veri toplama aracı olarak anket kullanılmıştır. Veriler, İstanbul'da faaliyet gösteren bir İŞKUR hizmet merkezine başvuran ve başvuru öncesi çalışma deneyimi bulunan işçilerden elde edilmiştir. Araştırmanın bir işletme bünyesinde değil de bir İŞKUR hizmet merkezinde gerçekleştirilmesi sayesinde, veriler, daha önce farklı sektör ve işletmelerde çalışmış ve böylece temsil kabiliyeti daha yüksek bir örneklem kitlesinden elde edilmiş olmaktadır. 30 günlük süre boyunca İŞKUR'a başvuran adaylardan anketi doldurmaları rica edilmiştir. Toplam 306 kişiye anket verilmiş ve bunlardan 248 adedi geri alınabilmiştir ve uygulanamaz düzeyde eksik veri içeren anketler ayıklandıktan sonra geriye 215 adet anket formu kalmıştır. Böylece araştırmanın örneklem sayısı 215 olarak belirlenmiştir.

Verilerin analizinde, çeşitli istatistiki yöntemler kullanılmıştır. Öncelikle, sendikalaşma eğilimi, baskı etkisi ve ikame etkisi düzeylerini tespit etmek amacıyla tanımlayıcı istatistiklerden yararlanılmıştır. Daha sonra bağımlı değişken sendikalaşma eğilimini ikame ve baskı etkilerinden hangisinin daha güçlü bir şekilde açıkladığını bulgulamak için hiyerarşik çoklu doğrusal regresyon analizi kullanılmıştır. Hiyerarşik regresyon analizinin kullanılmasındaki gaye, bazı kontrol değişkenlerinin analize dâhil edilmesinden ileri gelmiştir. İşçilerin yaş, cinsiyet, ücret düzeyi, daha önce sendika üyesi olup olmadığı, tam zamanlı mı yoksa kısmi zamanlı mı çalıştığı, işyeri büyüklüğü gibi bağımsız değişkenlerin kontrol değişkeni olarak analize dâhil edilmesi, ilgili açıklayıcı değişkenlerin (ikame ve baskı etkisi) bağımlı değişken sendikalaşma eğilimini tam olarak ne ölçüde açıkladığını görmeyi sağlayacaktır. Hiyerarşik regresyon analizi, bulgular kısmında da görüleceği üzere, ileriye doğru (forward) yöntemiyle gerçekleştirilmiştir. Bu yöntemin sağlayacağı fayda, açıklayıcı değişkenler (ikame ve baskı etkisi) hariç kontrol değişkenlerinden modele anlamlı katkı yapanları ve yapmayanları ayırarak, anlamlı katkı 
yapmayan değişkenleri model dışında bırakmasıdır. Yani hiyerarşik regresyon analizi sayesinde açıklayıcı değişkenler her halükarda model içinde tutulacak, ileriye doğru yöntemi sayesinde ise kontrol değişkenlerinden sadece yordam gücü olanlar modele dâhil edilecektir.

\section{2. Ölçme}

Sendikalaşma eğilimi, ikame etkisi ve baskı etkisini ölçmek için 5'li Likert tipi oluşturulan ifadelerden yararlanılmıştır. Sendikalaşma eğilimi katılımcılara yöneltilen şöyle bir ifade ile ölçülmüştür: Fırsatını bulduğum takdirde hiç düşünmeden sendikaya üye olurum. Fırsat kavramı burada özellikle tercih edilmiştir. Çünkü elde edilebilir bir sendika olmaksızın işçilerin sendikalaşma eğilimini ölçmek anlamsızdır (Turner \& D’Art, 2012: 35). Bu ifade, sendikalaşma eğilimini ölçmek için Amerikan ve İngiliz endüstri ilişkileri yazınında kullanılan ifadelerle uyumludur (Freeman, 2007; Turner \& D’Art, 2012).

İkame etkisi, şüphe yok ki çok çeşitli şekillerde ölçülebilirdi. Machin ve Wood (2005) kâra katılma gibi esnek ödeme seçeneklerinin kullanılmasını, ortak danışma kurullarının ve problem çözümünde grup toplantılarının yapılmasını ikame etkisi bağlamında değerlendirmiştir. Oysa bu uygulamaların yapılıp yapılmaması bize ikame etkisinin gerçek boyutu hakkında çok az şey söyler. İkame etkisi, en temel anlamıyla, işverenlerin daha iyi ücret ve çalışma koşulları sağlayarak sendikayı devre dışı bırakmasıdır (Fiorito, 2001). Bunu yaparken kullandığı 'dil' tekilci bir söylem içerir. Yani işverenlerin (dolayısıyla İKY'nin) tekilci ve bireyci bir kimliğe sahip olduğu söylenebilir (Geare, vd., 2006, 2009; Guest, 1987; Legge, 1995; Purcell, 1993; Y1ldırım, 1997). Dolasıyla gerçek bir ikame etkisinden söz ediliyorsa, işçiler arasında mutlaka sendikanın ihtiyaç dışı kaldığı yönünde bir algının bulunması gerekmektedir. Bu bağlamda, İKY'nin tekilci bir felsefeye sahip olmasının ne ölçüde işçilere yansıdığını, ücretler bakımından işverenlerin ne ölçüde ikame edici bir etkiye sahip olduğu ve İKY'nin sendikaya göre ne ölçüde ikame edici bir temsil mekanizması içerdiğinin bulunmasına ihtiyaç vardır. $\mathrm{Bu}$ doğrultuda, ikame etkisini ölçmek için şu ifadelerden yararlanılmıştır: 1) Daha önce çalıştı̆̆ım işyerindeki yöneticiler, işçilerin çıkarlarını yeterince düşündüğünden sendikaya ihtiyaç yoktu, 2) Daha önce çalıştı̆̆ım işyerinde; işveren yeterli ücreti verdiğinden sendikaya ihtiyaç yoktu, 3) Daha önce çalıştı̆̆ım işyerindeki İnsan Kaynakları Yönetimi birimi işçileri sendikadan daha iyi temsil ediyordu.

Son olarak baskı etkisinin nasıl ölçüldüğünden söz etmek gerekmektedir. Baskı etkisi (suppression effect, anti-unionism, employer opposition, employer resistance) özellikle Amerikan ve İngiliz endüstri ilişkileri yazınında yeterince tartışılmış bir konudur (Bronfenbrenner, 2009; Bronfenbrenner \& Juravich, 1994; Gall, 2004; Gall \& McKay, 2001; Freeman, 2007; Freeman \& Kleiner, 1988; Kelly, 1998; Moody, 2009; Robinson, 2008; Roche, 2001). Bu etki, işverenlerin sendikadan kurtulmak adına kullandıkları ve genellikle yasadışı olan uygulamaları konu alır (Fiorito, 2001: 335). İşçilerin bask1 etkisinde kalıp kalmadıklarını anlamanın yolu, bu tip uygulamalara ne ölçüde maruz kaldıklarının bilinmesine bağlıdır. Böyle durumlarla karşılaşan işçiler, sendikaya üye 
olmayı büyük bir risk olarak görürler (Bronfenbrenner, 2009). Bu risk işten atılma gibi oldukça güçlü bir baskı duygusu içerebileceği gibi, işverenle arasının açılması gibi görece düşük bir risk içerebilir. Dolayısıyla baskı etkisi, şu ifadelerle ölçülmeye çalışılmıştır: 1) Daha önce çalıştı̆̆ım işyerindeki yöneticiler sendikadan hoşlanmıyordu; 2) Daha önce çalıştı̆̆ım işyerinde ĕger sendikaya üye olsaydım yönetimle aram bozulurdu; 3) Daha önce çalıştı̆̆ım işyerinde eğer sendikaya üye olsaydım işten atılırdım.

\section{3. Örneklemin Niteliğ ${ }^{4}$}

215 katılımcının \%68,8'i erkek, \%32,2'si kadındır ve \%54,9'u evli, \%44,7'si bekâr konumundadır. \%25,6's1 ilkokul, \%28,3'ü ortaokul, \%30,2'si lise, \%7,5'i ön lisans, $\% 7,1$ 'i lisans ve \%0,9'u lisansüstü düzeyinde eğitim almıştır. \%5,6’s1 20 yaşın altında, \%36'sı 20-29 yaş arasında, \%39,7'si 30-39 yaş arasında, \%17,3'ü 40-49 yaş arasında ve $\% 1,4$ 'ü 50 yaş ve üzerinde bulunmaktadır. Örneklemin \%49,7'si bir ay veya daha az bir süredir iş aramakta, \%78'i altı ay veya daha az bir süredir iş aramakta ve \%86,1'i on iki ay veya daha az bir süredir iş aramaktadırlar. Örneklemin \%86,4'ünün daha önce düzenli bir çalışması olmuştur. Çalışma hayatında bulunanlardan \%11,8'inin 1 yıl veya daha az, \%30,4'ünün 2-5 yıl arasında, \%24,5'inin 6-10 yıl arasında, \%21,1'inin 11-20 y1l arasında ve \%12,3'ünün 21 yıl veya daha fazla çalışma deneyimi bulunmaktadır. Çalışma deneyimi olanların en son çalıştığ 1 şirketteki net ücret düzeyine bakıldığında, \%17,3'ü 1000 TL veya daha az, \%57,2'si 1001-1500 TL arasında, \%15,4'ü 1501-2250 TL arasında, \%8,2'si 22513000 TL arasında ve \%1,9'unun 3001 TL ve üstü net ücret aldıkları görülmüştür. Çalışma deneyimi olanların \%75'i kendisini 'işçi' veya 'personel' statüsünde, \%22,6'sı ustabaş1 veya orta düzey yönetici statüsünde ve $\% 2,4$ 'ü yönetici statüsünde konumlandırmıştır. En son istihdam olunan sektörlere bakıldığında, işçi adaylarının \%4,7'sinin tarım, \%39,5'inin sanayi, \%4,2'sinin inşaat ve \%30,7'sinin hizmet sektöründe çalıştıklarına tanık olunmuştur. İş bulmayı umdukları sektörlere bakıldığında ise, \%2,9'unun tarım, \%38,8'inin sanayi, \%2,4'ünün inşaat ve \%55,9'unun hizmet sektörüne yönelik olduğu görülmektedir. En son çalışılan şirketteki firma büyüklüklerine bakıldığında, \%28'inin 10 kişi veya daha az, \%33,6'sının 11-50 kişi arasında, \%22,7'sinin 51-250 kişi arasında ve $\% 15,6$ 'sının 251 veya daha fazla işçinin çalıştı̆̆ firmalarda istihdam olduklarına şahit olunmaktadır. Daha önce çalışma deneyimi olanların sadece \%1,4’ü en son çalıştı̆̆ işyerinde sendika üyesi olarak çalışmıştır ve sadece \% 7 'si daha önce herhangi bir zamanda sendika üyesi olmuştur. Son olarak, daha önceki çalışma şekli tam zamanlı olanların oranı $\% 90$, kısmi zamanlı olanların oranı ise \%10 olarak tespit edilmiştir.

Bu çalışmadaki örneklem, Kıllç ve Yıldız (2015) tarafindan gerçekleștirilen "İs arayanların sendika talebi ve sendika algısı: Türkiye'deki temsil boşluğu hakkinda bazı işaretler” başlıklı çalışmada kullanılan örneklem ile aynıdır. Fakat analiz edilen ölçekler ve ilişkiler birbirinden farklıdır. 


\section{Bulgular}

Bulgulara geçmeden önce ikame ve baskı etkisi ölçeklerinin güvenirlik değerlerinin verilmesi uygun olacaktır. Bu ölçeklerin güvenirlik değerleri daha önce kontrol edilmiştir (Kılıç, 2014). Fakat ifadelerin örneklemin niteliği gereği bazı değişikliklere uğramasından bu kontrol yeniden yapılmıştır. İkame etkisinin ve baskı etkisinin ölçek güvenirlik değeri daha önceki çalışmaya nazaran görece düşük çıksa da oldukça memnun edici düzeydedir (İkame etkisi için Cronbach's Alpha: ,797; Baskı etkisi için Cronbach's Alpha: ,822).

\section{1. İkame ve Baskı Etkileri ve Sendikalaşma Eğiliminin Düzeyi}

$\mathrm{Bu}$ çalışmada ortaya çıkan temel bulgulardan birincisi sendikalaşma eğilimi ile ilgilidir. Tanımlayıcı istatistiklerden yararlanılarak sendikalaşma eğilimini ölçmeye çalıştığımız "fırsatını bulduğum takdirde hiç düşünmeden sendikaya üye olurum" şeklindeki ifadeye işçilerin önemli bir çoğunluğu $(\% 56,4)$ 'katılıyorum veya tamamen katılıyorum" şeklinde puanlamışlardır. Bu konuda nötr olanlar bir diğer deyişler 'ortadayım' seçeneğini işaretleyenler \%27,4 düzeyinde kalırken, ifadeye 'katılmayanlar veya hiç katılmayanlar' sadece \%16,1 düzeyinde kalmıştır. Nötr kalan \%27,4’lük kesimin vermiş oldukları puanları, diğer iki seçeneğin ağırlıklarına göre dağıttığımızda yaklaşık \%78 düzeyinde sendikalaşma eğiliminden söz etmek mümkündür.

İkame etkisi ile ilgili maddelere verilen yanıt dağılımlarına bakıldığında (Tablo 1), işçilerin maddelere katılma düzeyleri \%15 civarında olduğu görülmektedir. Katılmayanlar ise yaklaşık \%65 civarındadır. Nötr kalanları benzer bir yöntemle dağıtım yaptığımızda yaklaşık \%80 oranında bir ikame etkisinden söz edilemeyeceği anlaşılmaktadır. Yani işçilerin büyük çoğunluğu, daha önce çalıştıkları işletmelerde, ikame etkisi hissetmemişlerdir.

Tablo: 1

İkame Etkisi Maddelerinin Yanıt Dağılımları

\begin{tabular}{lccc}
\hline İkame Etkisi Maddeleri & $\begin{array}{c}\text { Hiç Katılmayanlar ve } \\
\text { Katılmayanlar }\end{array}$ & $\begin{array}{c}\text { Nötr } \\
\text { Kalanlar }\end{array}$ & $\begin{array}{c}\text { Katılanlar ve } \\
\text { Tamamen Katılanlar }\end{array}$ \\
\hline $\begin{array}{l}\text {...yöneticiler, işçilerin çıkarlarını yeterince } \\
\text { düşundüğ̈̈nden sendikaya ihtiyaç yoktu }\end{array}$ & 65,6 & 17,6 & 16,8 \\
\hline $\begin{array}{l}\text {...işveren yeterli ücreti verdiğinden sendikaya } \\
\text { ihtiyaç yoktu }\end{array}$ & 64,6 & 21,3 & 14,2 \\
\hline $\begin{array}{l}\text {.. İnsan Kaynakları Yönetimi birimi işçileri } \\
\text { sendikadan daha iyi temsil ediyordu. }\end{array}$ & 66,3 & 19,7 & 14,0 \\
\hline
\end{tabular}

Büyük çoğunluğunun ikame etkisine maruz kalmadığı anlaşılan işçilerin, bask1 etkisine maruz kalma konusundaki düşünceleri oldukça farklıdır. Nitekim Tablo 2'de de görüleceği üzere işçilerin \%61,1'i yöneticilerinin sendikadan hoşlanmadığını, \%57,1'inin sendikaya üye olduğu takdirde yönetimle arasının bozulacağını ve \%50,5 gibi önemli bir 
çoğunluğunun işten atılacağı endişesi taşıdığı anlaşılmaktadır. Daha önceki tanımlayıcı istatistiklerde uyguladığımız gibi burada da nötr kalanları diğerleri içine dağıttığımızda bu oranlar oldukça yükselmektedir. Mesela sendikaya üye olduğu takdirde işten atılacağını düşünenlerin oranı \% 70'in üzerine çıkmaktadır.

Tablo: 2

Baskı Etkisi Maddelerinin Yanıt Dağılımları

\begin{tabular}{lccc}
\hline Baskı Etkisi Maddeleri & $\begin{array}{c}\text { Hiç Katılmayanlar ve } \\
\text { Katılmayanlar }\end{array}$ & $\begin{array}{c}\text { Nötr } \\
\text { Kalanlar }\end{array}$ & $\begin{array}{c}\text { Katılanlar ve Tamamen } \\
\text { Katılanlar }\end{array}$ \\
\hline ...yöneticiler sendikadan hoşlanmıyordu & 12,5 & 26,3 & 61,1 \\
\hline $\begin{array}{l}\text { a.sendikaya üye olsaydım yönetimle } \\
\text { aram bozulurdu }\end{array}$ & 14,7 & 28,2 & 57,1 \\
\hline $\begin{array}{l}\text {...eğer sendikaya üye olsaydım işten } \\
\text { atılırdım }\end{array}$ & 20,4 & 29,1 & 50,5 \\
\hline
\end{tabular}

\section{2. İkame ve Baskı Etkilerinin Sendikalaşma Eğilimiyle İlişkisi}

İkame ve baskı etkilerinin sendikalaşma eğilimi ile ilişkisini ölçmek amacıyla ileriye doğru (forward) hiyerarşik çoklu doğrusal regresyon analizinden yararlanılmıştır. Tablo 3'te gösterilen model özetinde görüleceği üzere, ikame ve bask1 etkilerinden oluşan bağımsız değişkenler, bağımlı değişken sendikalaşma eğilimini anlamlı fakat zayıf bir şekilde açıklamaktadır (R2: ,101).

Tablo: 3

Model Özeti

\begin{tabular}{ccccc}
\hline Model & $\mathrm{R}$ & $\mathrm{R} 2$ & Adjusted R2 & Std. Error of the Estimate \\
\hline 1 &, $318^{\mathrm{a}}$ &, 101 &, 087 & 1,062 \\
\hline
\end{tabular}

Tablo 4'te ANOVA testi sonuçları yer almaktadır. Tablodan da anlaşılmaktadır ki model istatistiksel açıdan anlamlıdır (p: ,001; F: 7,176).

Tablo: 4

ANOVA Testi Sonuçları

\begin{tabular}{|c|c|c|c|c|c|c|}
\hline \multicolumn{2}{|c|}{ Model } & Sum of Squares & df & Mean Square & $\mathrm{F}$ & Sig. \\
\hline \multirow{3}{*}{1} & Regression & 16,205 & 2 & 8,103 & 7,176 &, $001^{\mathrm{a}}$ \\
\hline & Residual & 144,528 & 128 & 1,129 & & \\
\hline & Total & 160,733 & 130 & & & \\
\hline
\end{tabular}

Tablo 5'teki regresyon analizi katsayıları göstermektedir ki ikame etkisi sendikalaşma eğilimini anlamlı bir şekilde etkilememektedir (p: ,230). Oysa baskı etkisi model için oldukça anlamlı bir açıklayıııdır (p: ,000; B: ,102; Beta: ,304). 
Tablo: 5

Regresyon Analizi Katsayıları

\begin{tabular}{|c|c|c|c|c|c|c|}
\hline \multirow{2}{*}{\multicolumn{2}{|c|}{ Model }} & \multicolumn{2}{|c|}{ Unstandardized Coefficients } & \multirow{2}{*}{$\begin{array}{c}\text { Standardized Coefficients } \\
\text { Beta }\end{array}$} & \multirow{2}{*}{$\mathrm{t}$} & \multirow{2}{*}{ Sig. } \\
\hline & & $\mathrm{B}$ & Std. Error & & & \\
\hline \multirow{3}{*}{1} & (Constant) & 2,846 & ,338 & & 8,428 & ,000 \\
\hline & İkame Etkisi &,- 035 & ,029 &,- 101 & $-1,206$ & ,230 \\
\hline & Bask1 Etkisi & ,102 & ,028 & ,304 & 3,622 & ,000 \\
\hline
\end{tabular}

Uygulanan regresyon analizinin ileriye doğru (forward) yöntemiyle gerçekleştirilmesi, modelden dışlanan değişkenlerin de gösterilmesini gerektirmektedir. Tablo 5'te görüldüğü üzere, kontrol değiş̧kenlerinden hiçbirisi model içinde yer almamıştır. Tablo 6'da ise dışlanan bu değişkenlere ait bazı detaylar bulunmaktadır. Burada da açıkça görüldügü üzere, kontrol değişkenlerinden hiçbirisi, modele anlamlı bir katk1 yapmamıştır.

Tablo: 6

Dışlanan Değişkenler

\begin{tabular}{|c|c|c|c|c|c|c|}
\hline \multirow{2}{*}{\multicolumn{2}{|c|}{ Model }} & \multirow{2}{*}{ Beta In } & \multirow{2}{*}{$\mathrm{t}$} & \multirow{2}{*}{ Sig. } & \multirow{2}{*}{ Partial Correlation } & \multirow{2}{*}{$\begin{array}{c}\text { Collinearity Statistics } \\
\text { Tolerance }\end{array}$} \\
\hline & & & & & & \\
\hline & Cinsiyet &, $004^{\mathrm{a}}$ & 050 & ,960 & ,004 & ,941 \\
\hline & Eğitim & $-118^{\mathrm{a}}$ & $-1,415$ & 159 &,- 125 & 1,000 \\
\hline & Yaş &, $059^{\mathrm{a}}$ &, 684 & ,495 &, 061 &, 943 \\
\hline & Ücret &,$- 027^{\mathrm{a}}$ &,- 322 & ,748 &,- 029 & ,995 \\
\hline \multirow[t]{5}{*}{1} & Pozisyon &,$- 028^{\mathrm{a}}$ &,- 333 &, 739 &,- 030 & 997 \\
\hline & Sektör &,$- 062^{\mathrm{a}}$ &,- 741 &, 460 &,- 066 & (993 \\
\hline & İşletme Büyüklüğü &, $087^{\mathrm{a}}$ & 1,023 & ,308 &, 090 & ,980 \\
\hline & Sendika Üyeliği & $149^{\mathrm{a}}$ & 1,779 & ,078 &, 156 & ,988 \\
\hline & Çalışma Şekli &, $044^{\mathrm{a}}$ &, 523 & ,602 &, 046 & ,998 \\
\hline
\end{tabular}

\section{Tartışma ve Sonuç}

Sendikal yoğunluktaki gerilemeyi açıklamak için yazında çok sayıda varsayım kullanılmaktadır. Bunlardan bir kısmı, post-Fordizm ve post-modernizm gibi "yapısal" bir değişimi, bir diğer deyişle geri döndürülemez bir dönüşümü vurgularlar (Beck, 1987; Brown, 1990; Troy, 2004). Bu söylemler, üstü açık ya da örtülü, örgütlü toplumların yok olmaya yüz tuttuğunu ve sendikaların yavaş yavaş tarih sayfalarına karışacaklarını iddia etmektedirler. Daha bireyselleşmiş bir toplum ve işçi sınıfi, hizmetler sektörünün oransal artışıyla sendikaların geleneksel olarak güçlü oldukları istihdam alanlarının azalması, esnek çalışma biçimlerinin yaygınlaşması, kadın işçilerin oransal artışı ve üretimin daha küçük işyerlerine taşınması gibi çok sayıda argüman bahsi geçen dönüşümün temel unsurları olarak ele alınmaktadır. Öte yandan, işçi kolektivizminin tükenmediğini hatta uzun süredir durağan bir seyir izlediğini (Peetz, 2010), fakat ağır işveren direncine maruz kalan işçilerin ve sendika düşmanı çevrenin etkisiyle sendikal yoğunluğun azaldığını vurgulayanlar da vardır (Bryson \& Gomez, 2004; Bronfenbrenner, 2009; Freeman, 2007). 
Hatta eğreti istihdam türlerinin yaygınlaşması, azalan iş güvencesi, işçiler aleyhine bozulan gelir dağılımı gibi gelişmelerin işçilerin sendika ihtiyacını arttırdığı iddia edilmektedir (Charlwood, 2002, 2003; Robinson, 2008). Dahası, sendikaların böyle elverişsiz emek piyasası koşullarını kendi lehine çevirmesinin mümkün olduğu vurgulanmakta ve bunun yolları geniş bir şekilde tartışılmaktadır (Gall, 2009; Frege \& Kelly, 2003).

Gerçekten de gerek Türkiye'de (Kılıç \& Yıldız, 2015) gerekse ABD, İngiltere ve Avustralya gibi ülkelerde (Haynes vd. 2006; Freeman, 2007) yüksek düzeyde bir temsil boşluğunun olduğu bilinmektedir. Bu çalışmanın bulgularında da görüleceği üzere işçilerin önemli bir kısmı ağır bir temsil boşluğuna maruz kalmaktadırlar. Zira işçilerin çoğunluğu sendikalaşma eğiliminde olmasına rağmen, en son çalıştıkları işletmede sendika üyesi olan işçilerin oranı sadece $\% 1,4$; daha önce herhangi bir zamanda sendika üyesi olanların oranı ise sadece $\% 7$ olarak tespit edilmiştir. En az \%56'lık bir sendikalaşma eğiliminin olduğu düşünülürse ve üstüne nötr kalanların dağıtımı yapıldığında eğilimin \%80'e yaklaştığı göz önüne alınırsa temsil boşluğunun derecesi hakkında az çok fikir sahibi olunabilir.

Temsil boşluğu konusunda yazanların ortak fikri, sendikasızlaşmadaki temel belirleyicilerden birisinin işveren direnci olduğudur. Gerçekten de bu araştırmanın bulguları da göstermektedir ki çalışma hayatında ağır bir baskı etkisi vardır. O kadar ki işçilerin yarısından fazlası sendikaya üye olduğunda işten atılacağını düşünmektedir. Hatta kararsızları bir tarafa bırakırsak bu oran \%70'in üzerine çıkmaktadır. Böyle bir baskı T.C. Anayasası da dâhil olmak üzere iş hukuku normlarına ve çoğulcu bir toplum yapısında bulunması gereken etik değerlere son derece aykırıdır ve üzerinde önemle durulması gereken bir sorundur. İkame etkisi konusuna gelince, işçilerin azınlığı (en fazla beşte biri) bu etki altındadır. Zira işçilerin çok azı; çıkar tanımları, ücretler ve temsil konularında ikame etkisi altında kalmışlardır. Bu veri aynı zamanda işçilerin yüksek düzeyde sendika ihtiyacına sahip olduğu anlamına gelmektedir.

Bu manzara, kapitalist bir çalışma ilişkisinde, işçilerin örgütlenme ihtiyaçlarının yaygın ve yapısal olduğu yönündeki görüşleri desteklemektedir. Tarihsel süreçte ve bugün itibariyle işçiler adına sendikalardan başka bir örgütlenme mekanizması da henüz geliştirilebilmiş değildir (D’Art \& Turner, 2003). Dolayısıyla sendikalar, asimetrik bir güç mücadelesini daha az asimetrik bir ilişkiye dönüştürebilecek yegâne kurumlar olarak durmaktadır. Bütün bu baskılara rağmen, sendikalar siyasi ve ekonomik güçlerini halen belli oranda korumaktadırlar. Ayrıca sendikalar halen gerek liberal ekonomi gerekse endüstriyel demokrasi için son derece kritik etkilere sahiptir.

Sendikalar, tarihsel süreçte birden çok kere düşüş ve yükseliş eğilimlerine konu olmuştur (Kelly, 1998). Mesela bugünkü post-modern argumanların benzeri iddialar 1930'larda da savunulmaktaydı: New Deal arifesinde, emek hareketinin can çekiştiği söylenmekteydi (Reder, 1988:107). Sendikaların uzun dalgalar yasasına konu olduğunu ve günümüzde 'dip' noktaya doğru yaklaştığını, gelecekte ise yeniden toparlanma potansiyeli olduğunu savunanlar, gerek devlet tarafindan uygulanan de-kolektivist uygulamaların ve kuralsızlaştırma stratejilerinin gerekse işverenlerin anti sendikacılık bağlamında 
uyguladıkları baskı etkisinin tersine dönebileceğini iddia etmektedirler. Bu gelişmelerin sendika ihtiyacını ve sendikalaşma eğilimini yükselteceğini ve uygun sendika stratejileriyle desteklendiğinde sürecin tersine işleyebileceğini savunmaktadırlar. Bu araştırmanın bulguları da bu tip iddiaları desteklemektedir. Gerçekten de sendikalaşma eğilimi baskı etkisinden önemli ölçüde etkilenmektedir. Yani işveren direncine maruz kalan işçilerin sendikalaşma eğilimleri bariz bir şekilde daha yüksektir. Bu durum elverişsiz koşulların bir referans çerçevesi olarak belirlendiğinde firsata dönüşebileceğini göstermektedir.

\section{Kaynaklar}

Badigannavar, V. \& J. Kelly (2005), "Why Are Some Uinon Organizing Compaigns More Succesful Than Others", British Journal of Industrial Relations, 43(3), 515-535.

Baruch, Y. (1998), “The Rise and Fall of Organizational Commitment”, Human Systems Management, 17(2), 135-143.

Beck, U. (1987), “Beyond Status and Class: Will There Be an Invidiualised Class Society?”, in: V. Meja, D. Misgeld \& N. Stehr (ed.), Modern German Sociology, New York: Columbia University Press, 340-356.

Blyton, P. \& P. Turnbull (2004), The Dynamics of Employee Relations, London: Palgrave Macmillan.

Braverman, H. (1998), Labor and Monopoly Capital (25th Anniversary Edition b.), New York: Monthly Review Press.

Bronfenbrenner, K. (2009), "No Holds Barred: The Intensification of Employer Opposition to Organizing”, EPI Briefing Paper, 235, Washington: Economic Policy Institute.

Bronfenbrenner, K. \& T. Juravich, (1994), "The Impact of Employer Opposition on Union Certification Win Rates", Working Paper, 113, Washington: Economic Policy Institute.

Brown, H.P. (1990), “Counter Revolution of Our Time”, Industrial Relations: A Journal of Economy and Society, 29(1), 1-14.

Bryson, A. \& R. Gomez \& P. Willman (2004), “The End of the Affair?: The Decline in Employers' Propensity to Unionize", in: J. Kelly \& P. Willman (ed.), Union Organization and Activity, London: Routledge, 129-149.

Charlwood, A. (2002), "Why Do Non-union Employees Want to Unionize? Evidence from Britain", British Journal of Industrial Relations, 40(3), 463-491.

Charlwood, A. (2003), "Willingness to Unionize amongst Non-union Workers", in: H. Gospel \& S. Wood (ed.), Representing Workers: Trade Union Recognition and Membership in Britain, London: Routledge, 51-71.

D’Art, D. \& T. Turner (2003), “Independent Collective Representation: Providing Effectiveness, Fairness, and Democracy in the Employment Relationship", Employee Responsibilities and Rights Journal, 15(4), 169-181.

Dundon, T. (2002), "Union Avoidance and Employer Hostility to Union Organizing in the UK", Proceedings of the 54th Annual Meeting, Atlanta: Industrial Relations Research Association Series, 233-242.

Dundon, T. \& D. Rollinson (2004), Employment Relations in Non-Union Firms, London: Routledge. 
Fiorito, J. (2001), "Human Resource Management Practices and Worker Desires for Union Representation", Journal of Labor Research, 22(2), 335-354.

Fiorito, J. (2003), "Union Organizing in the United States", in: G. Gall (ed.), Union Organizing: Campaingning for Trade Union Recognition, London: Routledge, 191-210.

Fox, A. (1974), Beyond Contract: Power, Work and Trust Relations, London: Faber \& Faber.

Freeman, R.B. (2007), "Do Workers Still Want Union? More Than Ever”, EPI Briefing Paper, 182, Washington: Economic Policy Institute.

Freeman, R.B. \& M.M. Kleiner (1988), "Employer Behavior in the Face of Union Organizing Drives", Working Paper Series, 2805, Cambridge: National Bureau of Economic Research.

Frege, C.M. \& J. Kelly (2003), "Union Revitalization Strategies in Comparative Perspective", European Journal of Industrial Relations, 9(1), 7-24.

Frege, C.M. \& J. Kelly (2004), “Union Strategies in Comprative Context”, C.M. Frege \& J. Kelly (ed.), Varieties of Unionism: Strategies for Union Revitalization in a Globalizing Economy, New York: Oxford University Press, 31-44.

Gall, G. (2002), "Employer Opposition to Union Recognition in Britain”, Proceedings of the 54th Annual Meeting, Atlanta: Industrial Relations Research Association Series, 243-256.

Gall, G. (2003), “Employer Opposition to Union Recognition”, in G. Gall (ed.), Union Organizing: Campaigning for Trade Union Recognition, London: Routledge, 79-96.

Gall, G. (2004), "British Employer Resistance to Trade Union Recognition”, Human Resorce Management Journal, 14(2), 36-53.

Gall, G. (2009), “What is to be Done with Union Organising?”, in G. Gall (ed.), Union Revitalisation in Advanced Economies: Assessing the Contribution of Union Organising, London: Palgrave Macmillan, 1-16.

Gall, G. \& S. McKay (2001), “Facing 'Fairness at Work': Union Perception of Employer Opposition and Response to Union Recognition", Industrial Relations Journal, 32(2), 94-113.

Gallie, D. \& A. Felstead \& F. Green (2001), "Employer Policies and Organizational Commitment in Britain 1992-97”, Journal of Management Studies, 38(8), 1083-1101.

Geare, A. \& F. Edgar \& I. McAndrew (2006), "Employment Relationships: Ideology and HRM Practice", The International Journal of Human Resource Management, 17(7), 11901208.

Geare, A. \& F. Edgar \& I. McAndrew (2009), "Workplace Values and Beliefs: An Empirical Study of Ideology, High Commitment Management and Unionisation”, The International Journal of Human Resource Management, 20(5), 1146-1171.

Greenwood, M.R. (2002), "Ethics and HRM: A Review and Conceptual Analysis”, Journal of Business Ethics, 261-278.

Guest, D.E. (1987), "Human Resource Management and Industrial Relations”, Journal of Management Studies, 14(5), 503-521.

Haynes, P. \& P. Boxal \& K. Macky (2006), "Union Reach, the 'Representation Gap' and the Prospects for Unionism in New Zeland”, Journal of Industrial Relations, 48(2), 193-216.

Heery, E. \& J. Kelly \& J. Waddington (2003), “Union Revitalization in Britain”, European Journal of Industrial Relations, 9(1), 79-97. 
Kaufman, B.E. (2008), "Paradigms in Industrial Relations: Original, Modern and Versions inbetween", British Journal of Industrial Relations, 46(2), 314-339.

Kelly, J. (1998), Rethinking Industrial Relations: Mobilization, Collectivism and Long Waves, London: Routledge.

Kılıç, S. (2014), "Mobilizasyon Teorisi ve Kolektivizm Bağlamında Endüstri İlişkilerinde 'Dönüşüm': Perakende Sektöründe Bir Araştırma”, Yayınlanmamış Doktora Tezi, İstanbul Üniversitesi Sosyal Bilimler Enstitüsü.

Kılıç, S. \& K. Yıldız (2015), “İş Arayanların Sendika Talebi ve Sendika Algısı: Türkiye'deki Temsil Boşluğu Hakkında Bazı İşaretler”, Siyaset Ekonomi ve Yönetim, 16. Çalışma Ekonomisi ve Endüstri İlişkileri Kongresi Özel Sayısı, 191-204.

Legge, K. (1995), Human Resource Management: Rhetorics and Realities, Basingstoke: Macmillan Press.

Machin, S. \& S. Wood (2005), "Human Resource Management as a Substitute for Trade Unions in British Workplaces", Industrial and Labor Relations Review, 58(2), 201-218.

McLoghlin, I. \& S. Gourlay (1992), "Enterprise without Unions: the Management of Employment Relations in Non-union Firms", Journal of Management Studies, 29(5), 669-691.

Moody, K. (2009), "Union Organising in the US: New Tactics, Old Barriers", in G. Gall (ed.), The Future of Union Organising: Building for Tomorrow, Basingstoke: Palgrave Macmillan, $10-27$.

Peetz, D. (2010), “Are Individualistic Attitudes Killing Collectivism?” Eurepean Review of Labour and Research, 16(3), 383-398.

Purcell, J. (1993), “The Challenge of Human Resource Management for Industrial Relations Research and Practice", The International Journal of Human Resource Management, 4(3), 511-527.

Robinson, I. (2008), “What Explains Unorganized Worker's Growing Demand for Unions?”, Labor Studies Journal, 33(3), 235-243.

Roche, W.K. (2001), "Accounting for the Trend in Trade Union Recognition in Ireland", Industrial Relations Journal, 32(1), 37-54.

Roche, W.K. (1998), "Between Regime Realignment and Fragmentation: Irish Industrial Relations in the 1990s", Industrial Relations Journal, 29(2), 112-125.

Thompson, P. \& B. Harley (2007), "HRM and the Worker: Labor Process Perspective", P. Boxal, J. Purcell and P. Wright (ed.), The Oxford Handbook of Human Resource Management, New York: Oxford University Press, 147-165.

Troy, L. (2004), The Twilight of the Old Unionism, New York: Sharpe Inc.

Turner, T. \& D. D'Art (2012), "Public Perceptions of Trade Unions in Countries of the European Union: A Casual Analysis", Labor Studies Journal, 37(1), 33-55.

Yıldırım, E. (1997), Endüstri İlişkileri Teorileri, Sakarya: Değişim. 